\title{
AKULTURASI BUDAYA PADA POLA PERMUKIMAN TRADISIONAL DI KAMPUNG GANTARANG LALANG BATA KABUPATEN KEPULAUAN SELAYAR
}

\author{
Cultural Acculturation on Traditional Settlement Patterns in \\ Kampong Gantarang Lalang Bata Selayar Islands Regency
}

\section{Washilah Sahabudin ${ }^{1}$ and Fadhil Surur ${ }^{2}$}

Diterima: 14 September 2017

Disetujui: 16 Agustus 2018

\begin{abstract}
Abstrak : Proses komunikasi dan interaksi antara masyarakat pribumi dengan masyarakat luar melahirkan bentuk akulturasi budaya yang khas. Proses tersebut juga terjadi pada masyarakat tradisional di Gantarang Lalang Bata. Sebagai pusat kerajaan, mereka telah melakukan interkasi dengan masyarakat dengan budaya yang berbeda antara Jawa, Melayu dan orangorang Eropa. Tujuan penelitian ini adalah mengkaji bentuk akulturasi budaya yang mempengaruhi perkembangan pola permukiman Gantarang Lalang Bata. Teknik pengumpulan data dilakukan melalui data primer dan data sekunder. Teknik analisis yang digunakan adalah analisis deskriptif dengan mengkonstruksikan realitas dan makna kultural serta pendekatan sense of place. Hasil penelitian menunjukkan bahwa pola permukiman Gantarang Lalang Bata membentuk asosiasi antar unsur manusia dan unsur alam. Sistem keragaman budaya yang berbeda antara Hindu, Jawa, Eropa dan Arab memiliki pengaruh terhadap pembentukan lanskap. Budaya corak Hindu yang mengarah pada tradisi pakammik, unsur Jawa merujuk pada bangunan masjid, keberadaan meriam sebagai atribut unsur Eropa dan tradisi serta tata ruang berasosiasi dengan pengaruh Arab. Pengaruh budaya Jawa Islam menjadi sisi yang paling dominan mempengaruhi pola permukiman dan membentuk mekka keke sebagai sense of place dari kawasan kampung tua Gantarang Lalang Bata.
\end{abstract}

\section{Keyword in Bahasa: budaya, permukiman, tradisional}

\begin{abstract}
The process of communication and interaction between indigenous peoples and the outside community gives birth to a distinctive form of cultural acculturation. The process also occurs in traditional communities in Gantarang Lalang Bata. As the center of the kingdom, they have been interacting with people with different cultures between Java, Malay, and Europeans. The purpose of this research is to study the form of cultural acculturation that influences the development. Data collection technique is done through primary data and secondary data. The analytical technique used is descriptive analysis by constructing reality and cultural meaning and approach of a sense of place. The results showed that the pattern of settlement Gantarang Lalang Bata formed an association between human elements and natural elements. Different cultural diversity systems between Hindus, Javanese, Europeans, and Arabs have an influence on the formation of landscapes. Cultural style of Hindu that leads to the tradition of pakammik, the Javanese element refers to the mosque building, the existence of the cannon as an attribute of European elements and tradition and layout associated with Arabic influence. The influence of
\end{abstract}

1 Teknik Arsitektur UIN Alauddin Makassar, washilah@uin-alauddin.ac.id

2 Teknik Perencanaan Wilayah dan Kota UIN Alauddin Makassar

Korespondensi: washilah@uin-alauddin.ac.id; , fadhil.surur@uin-alauddin.ac.id 
Javanese culture - Islam became the most dominant side influenced settlement pattern and formed mekka keke as a sense of place from the old village of Gantarang Lalang Bata.

Keywords: culture, settlement, traditional

\section{PENDAHULUAN}

Pada dasarnya lanskap tidak ditentukan hanya pada batasan alam, akan tetapi lanskap juga menempatkan identitas tertentu berdasarkan persepsi manusia, dimana identitas tersebut memiliki nilai sejarah, geomorfologi, budaya dan aspek lainnya yang melengkapi satuan ekologi (Vos \& Meekes, 1999). Lanskap sejarah adalah bagian dari suatu lanskap yang memiliki dimensi waktu di dalamnya, maka dapat memainkan peran penting dalam mendasari dan membentuk tradisi budaya, ideologikal, dan etnikal dalam suatu kelompok masyarakat (Nurisjah \& Pramukanto, 2001). Secara umum lanskap sejarah dapat dirasakan dengan dua cara yaitu dengan pendekatan tangible sebagai material yang nyata dan intangible yang tidak berwujud dalam kejiwaan dan pengalaman artistik (Zonneveld, 1981).

Pulau Selayar yang terpisah dari Pulau Sulawesi berada pada lalu lintas maritim dan menjadi salah satu daerah yang penting dalam sejarah perdagangan di Indonesia. Pada abad ke 13 Kerajaan Gantarang Lalang Bata sebagai kerajaan besar di Selayar mendapat pengaruh dari Kerajaan Majapahit (Said, Ramli \& Sumantri, 2007). Pada masa kepemimpinan Radja Gantarang Pangali Patta Radja pada 1605 menerima secara resmi agama Islam yang disyiarkan oleh Datuk Ri Bandang dengan pendekatan kelembagaan dan kemudian berkembang dengan pesat (Ilyas, 2014). Datok Ri Bandang menyiarkan Islam dengan rute dari Kerajaan Luwu menuju ke Kerajaan Gowa melalui Teluk Bone, akan tetapi terlebih dahulu singgah di Pulau Selayar (Yunus, 2014). Hingga saat ini ragam nilai sejarah peradaban Kerajaan Gantarang Lalang Bata masih dapat diamati.

Perkembangan sejarah Kerajaan Gantarang Lalang Bata tidak terlepas dari adanya bentuk hubungan komunikasi dan interkasi dengan masyarakat luar. Komunikasi antarbudaya adalah komunikasi antara orang-orang yang berbeda budaya baik dalam arti ras, etnik, atau perbedaan perbedaan sosio ekonomi (Tubss \& Sylvia, 2001). Dalam akulturasi budaya terjadi proses sosial yang timbul bila suatu kelompok manusia dengan suatu kebudayaan tertentu dihadapkan dengan unsur-unsur dari suatu kebudayaan asing dengan sedemikian rupa, sehingga unsur-unsur kebudayaan asing tersebut lambat laun diterima dan diolah kedalam kebudayaan sendiri tanpa menyebabkan hilangnya kepribadian budaya itu sendiri (Koentjaraningrat, 1990). Bentuk interaksi masyarakat dengan luar kawasan pada masa lalu memberikan pengaruh pada perkembangan pola tata ruang kawasan.

Kampung Gantarang Lalang Bata berada pada daerah yang bertebing dan masih mendapat pengaruh dari ekosistem pesisir. Sehingga menciptakan harmonisasi ruang antara unsur manusia dan alam. Lanskap budaya adalah bagian dari lanskap sejarah, dimana lanskap budaya merepresentasikan bentuk kombinasi antara alam dan manusia (Wang, 2015). Warisan budaya dianggap sebagai sumberdaya yang berharga dan tidak tergantikan, sekaligus menjadi identitas pribadi dalam meningkatkan kualitas hidup (Lowenthal, 2006). Lanskap budaya memberikan peluang baru dalam pengembangan situs budaya di pedesaan yang masih berfungsi (Fowler, 2003). Berdasarkan uraian tersebut, maka tujuan dari penelitian ini adalah mengkaji bentuk akulturasi budaya yang mempengaruhi perkembangan pola tata ruang tradisional di kampong Gantarang Lalang Bata.

\section{METODE}

Penelitian dilaksanakan di kampung tua Gantarang Lalang Bata yang berada di Dusun Gantarang Desa Bontomarannu Kecamatan Bontomanai. Strategi pendekatan 
dalam penelitian ini menggunakan pendekatan deskriptif kualitatif. Teknik pengumpulan data dilakukan melalui data primer dan data sekunder. Data primer berupa wawancara dan observasi lapangan, sedangkan data sekunder melalui kajian literatur dan telaah dokumen. Penelitian ini merupakan jenis penelitian eksploratif yang menggambarkan bentuk kajian secara rinci. Pendekatannya berupa penelitian kualitatif, yang berdasarkan Arikunto (2002), antara lain bercirikan menekankan pada setting alami, menggunakan non probabilities sampling, dan menekankan proses dari pada hasil. Data-data diperoleh berdasarkan kajian lapangan dan referensi yang ada, yang selanjutnya dianalisis dengan menggunakan analisis deskriptif dengan mengkonstruksikan realitas dan makna kultural (Somantri, 2005) serta bentuk sense of place dan image of the city (Lynch, 1960 dalam Aryanto et.al, 2004). Review dan wawancara ulang terhadap narasumber dari penelitian awal juga dilakukan untuk memperkuat atau menegaskan hipotesis yang dibuat sesuai dengan fenomena di lapangan.

\section{HASIL DAN PEMBAHASAN}

Secara geografis kampong tua Gantarang Lalang Bata terletak $6^{\circ} 05^{\prime} 52,7^{\prime \prime L S}$ $120^{\circ} 32$ '51,3"BT dengan ketinggan berkisar 334 mdpl. Bentang alam dipengaruhi oleh ekosistem pesisir, dimana berada ditengah hutan dan kebun dengan kondisi lahan yang berbukit. Di sebelah timur mengarah ke pantai bertebing dan Laut Flores. Peruntukan penggunaan lahan di sekitar kawasan dimanfaatkan untuk kegiatan hutan rakyat dan sebagian menjadi hutan konservasi perairan. Kampung tua tersebut dapat dijangkau dengan menggunakaan jalur darat dari Benteng (ibukota Kabupaten Kepulauan Selayar) sekitar $15 \mathrm{~km}$ ke arah timur. Jumlah penduduk berkisar 40 kepala keluarga yang secara keseluruhan menganut agama Islam. Luas kampung tua di Dusun Gantarang ini mencapai 4,82 ha. Berdasarkan peraturan daerah nomor 5 tahun 2012 tentang Rencana Tata Ruang Wilayah Kabupaten Kepulauan Selayar menetapkan kawasan Gantarang Lalang Bata sebagai peruntukan kawasan pariwisata budaya dalam rangka memelihara keberlanjutan objek warisan budaya yang ada di kawasan tersebut terutama masjid tua Gantarang.

Sumber : ArGIS 10

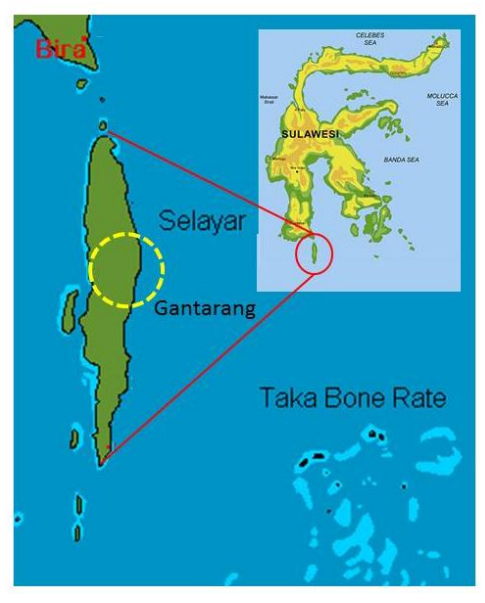

\section{Gambar 1. Orientasi Wilayah Penelitian}

\section{Sejarah Perkembangan}

Pulau Selayar memiliki beberapa kerajaan yaitu Gantarang, Buki, Putabangun, dan Saluk. Mereka telah membangun kerjasama perdagangan dengan berbagai wilayah di Nusantara. Orang Selayar sebagai bangsa pedagang yang terkenal sebagai pelaut yang 
menjelajahi kepulauan Nusantara dari Singapura sampai New Guinea (Asba, 2005). Pada awalnya kampung tua Gantarang Lalang Bata merupakan pusat administrasi dan pertahanan bagi kerajaan Gantarang. Walaupun memiliki wilayah kekuasaan sendiri, kerajaan ini tetap mendapat pengaruh dari Kerajaan Gowa. Segala bentuk hubungan diplomatik, raja tetap harus berkomunikasi dengan Kerajaan Gowa (Yunus, 2014). Selain itu juga pernah dikuasai oleh kerajaan Bone dan Ternate, dari situlah terjadi interelasi hubungan yang dinamis, berfluktiatif, saling memberi pengaruh antara kekuatan politik tersebut (Ilyas, 2014). Sekitar 1500 Selayar tampaknya telah menjadi pengikut Bone. Antara 1512 dan 1675 Selayar itu bergantian ditundukkan oleh Makassar (Gowa) dan Ternate. Tahun 1512 pulau Selayar termasuk dalam wilayah kekuasaan Gowa. Pada masa pemerintahan Daeng Matanre Karaeng Manguntungi “Tumaparrisi Kallonna” Selayar di taklukkan. Tahun 1580 Ternate mendatangi pulau Selayar yang dipimpin oleh Babullah sebagai panglima perang. Pada tahun itu posisi Selayar dianeksasi kerajaan Ternate (Heersink, 1995 dalam Ilyas 2014).

Berdasarkan sejarah kerajaan ini dinahkodahi oleh 9 (sembilan) raja yaitu Sultan Pangali Patta Raja, Daeng Maronrong, Daeng Paduni, Baso Ali Daeng Biraeng Karaeng Rahung, Paleha Daeng Karaeng, Cekele Daeng Manguntungi, Baso Opu, Muhammad Daeng Malawa dan Patta Bau Cendra Karaeng Pole. Letak strategis pusat kerajaan Gantarang sangat menguntungkan dalam strategi perang, dimana letaknya yang berada pada perbukitan akan menyulitkan serangan dari luar sebagai bentuk pertahanan, disisi lain memiliki dua pelabuhan alam yang langsung menghubungkan dengan jalur Laut Flores. Pada masa tersebut masyarakat setempat memiliki kepercayaan pada roh halus, leluhur dan benda-benda keramat yang diasosiakan sebagai wujud kepercayaan mereka, hal tersebut sebagai bentuk kuatnya pengaruh ajaran Pra-Islam (Ahmadin, 2006).

Masuknya agama Islam di Nusantara membuka babak baru perkembangan kerajaan. Sebagaimana disebutkan dalam kitab Negarakretagama, Selayar merupakan wilayah yang mendapat pengaruh Kerjaan Majapahit. Selanjutnya kedatangan pedagang Melayu Muslim dari Patani, Pahang dan Ujung Tanah sejak 1480 secara tidak langsung menjadi awal penyebaran Islam di Selayar (Said, Ramli \& Sumantri, 2007). Asal mula masuknya Islam yaitu pada tahun 1605 yang ditandai dengan kehadiran Dato' Ri Bandang melakukan perjalanan untuk mengislamkan Luwu, dalam perjalanan ke Makassar singgah dan mengislamkan Selayar. Kerajaan Gantarang yang dipimpin oleh Pangali Patta Raja menerima secara resmi agama Islam sebagai agama kerajaan pada tahun 1575 (Yunus, 2014).

Proses islamisasi secara kelembagaan diperkirakan pada tahun 1605. Berdasarkan data yang tertera dalam naskah Sejarah Kedatangan Dato ri Bandang koleksi Djinabong diriwayatkan bahwa kedatangan Dato ri Bandang untuk mengislamkan Raja Gantarang Selayar pada awalnya raja Gantarang menolak dengan alasan takut kepada raja Gowa. Namun Dato ri Bandang tetap memaksa mengislamkan Raja Gantarang sebelum mengislaman raja Gowa. Setelah resmi diterima Raja Gantarang menghadap ke Raja Gowa untuk menyampaikan bahwa Islam sudah diterima di wilayah kekuasaannya. Setelah kembali ke Selayar proses Islamisasi berkembang pesat dengan mengislamkan seluruh masyarakat Gantarang, dan kerajaan kecil lainnya yaitu Tanete, Batang Mata, Kadieng, Putabangung, Bontobangung, Layolo dan Buntu Barusu (Ilyas, 2014).

Masa pemerintahan Sultan Pangali Patta Raja, Kerajaan Gantarang menjadi pusat pemerintahan utama di Pulau Selayar, dengan jangkauan kekuasaan dari Selayar hingga Bulukumba. Kebijakan raja menyempurnakan nama Kerajaan Gantarang menjadi Kerajaan Gantarang Lalang Bata yang berate gang (jalan), tarang (terang), lalang (dalam) dan bata (pagar). Sehingga dianalogikan sebagai kampung yang dipagari menuju jalan yang terang. Pada masa tersebut sekaligus sebagai periode pesatnya perkembangan Islam. Namun 
wilayah kekuasaanya semakin menyempit setelah kedatangan penjajah Belanda. Pada masa tersebut pusat pemerintahan dipindahkan ke Bonea karena faktor aksesibiltas dan strategi perang yang dilakukan oleh Belanda. Pada dasarnya kampung tua Gantarang Lalang Bata mendapat pengaruh dari berbagai budaya antara lain kepercayaan pra Islam, Jawa, Melayu, Belanda dan agama Islam.

\section{Elemen Permukiman}

Berdasarkan lintasan ruang dan waktu, kampung tua Gantarang Lalang Bata hidup dan berkembang baik dari karakter masyarakat maupun fungsi ruangnya. Pada konteks tersebut dapat ditinjau sebagai sebuah kawasan budaya dengan keunikan sejarahnya. Lanskap budaya merupakan sebuah model interaksi antara manusia, sistem sosial, dan cara mereka mengorganisasikan ruang (Planchter dan Rossler, 1995). Kecenderungan kawasan budaya memperlihatkan pada kondisi ketergantungan terhadap alam, melalui adaptasi kegiatan manusia terhadap penggunaan ruang (Vos \& Meekes, 1999). Elemen pembentuk kawasan terdiri dari :

a. Elemen fisik; wujud elemen yang bersifat tangible. Dikategorikan menjadi elemen utama dan elemen pendukung.

Tabel 1. Elemen Fisik

\begin{tabular}{cll}
\hline No & Elemen & Keterangan \\
\hline & Elemen Utama & Dibangun pada tahun 1605 \\
1 & Masjid Awaluddin & Tumpukan batu setinggi $60 \mathrm{~cm}$, dianalogikan sebagai Kabbah \\
2 & Possi tanah (pusat kampung) & Kubangan berdiamater $50 \mathrm{~cm}$, dianalogikan sebagai Hajar Aswad \\
3 & Pakkojokang (tempat meraba) & Berada di sekitar masjid Awaluddin \\
4 & Kuburan Daro Ri Bandang & Terdapat nisan yang menggunakan tulisan arab \\
5 & Kompleks makam raja & Terdiri dari empat pintu \\
6 & Benteng pertahanan & Ruang terbuka di sekitar masjid \\
7 & Alun - alun & Tempat pelantikan raja \\
8 & Batu Karaeng & Meriam kecil yang berukuran 2 meter \\
9 & Latto & Dipercayai sebagai tapak kaki Nabi Muhammad SAW \\
10 & Tapak Kaki & Dibangun pada tahun 1605 \\
& Elemen Pendukung & \\
1 & Rumah Panggung & Rumah tradisional Bugis-Makassar \\
2 & Jalan & Prasarana pendukung permukiman \\
3 & Gerbang & Penanda kawasan \\
4 & Topografi & Lahan berbukit \\
5 & Vegetasi & Hutan dan kebun \\
\hline
\end{tabular}

Source: hasil survey, 2016
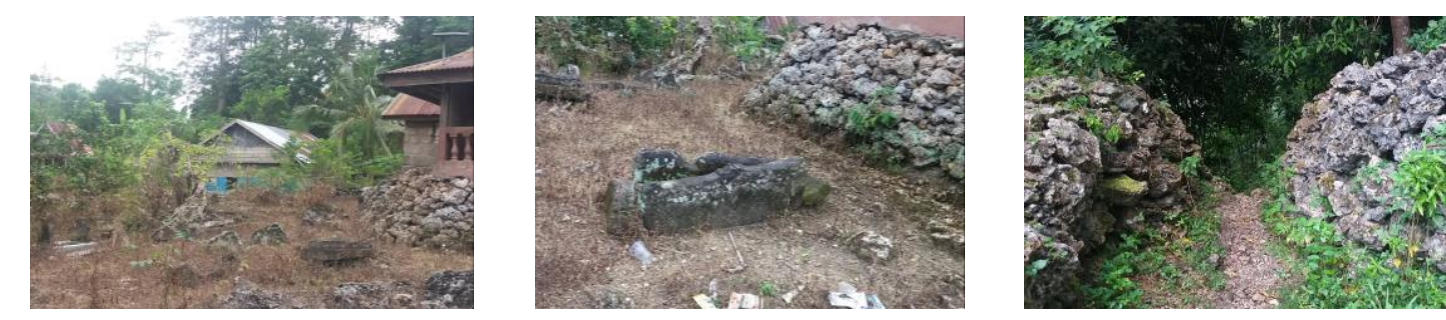

Sumber : hasil survey, 2016

Gambar 2. Elemen permukiman (a) benteng, (b) makam dan (c) permukiman 
b.Elemen Non fisik ; wujud elemen yang bersifat intangible. Hal ini berkaitan dengan ragam budaya lokal khas masyarakat setempat.

Tabel 2. Elemen Non Fisik

\begin{tabular}{cll}
\hline No & Elemen & Keterangan \\
\hline 1 & Jumatan & Pembacaan naskah khutbah \\
2 & Manasik haji & Ritual haji di sekitar masjid \\
3 & Idul Adha dan Idul Fitri & Pembacaan naskah khutbah \\
4 & Rate' - ammasa - barazanji & Pembacaan syair pujian Rasulullah pada acara maulid \\
5 & Perkawinan & nabi \\
6 & Khitanan & Adat Bugis-Makassar \\
\hline
\end{tabular}

Sumber: hasil survey, 2016

\section{Pola Tata Ruang Tradisional}

Kampung tua Gantarang Lalang Bata yang berada di perbukitan merupakan salah satu strategi dari bentuk alam dalam mempertahankan wilayah kerajaan. Letak strategis yang dikelilingi hutan dan kebun serta topografi laha yang terjal sehingga menyulitkan orang luar memasuki kawasan tersebut. Pada sisi timur dan barat secara langsung terhubung dengan pelabuhan alami yang dimanfaatkan sebagai jalur sirkulasi. Batas kampung yang ditandai dengan benteng mengikuti topografi wilayah, dimana hanya memanfaatkan lahan yang datar sebagai area bermukim. Sebaran permukiman mengikuti pola linear jalan yang saling berderet, sejajar dan memanjang pada sisi kiri dan kanan. Pola linier dengan jalan lurus yang menjadi unsur pengorganisir utama kemudian membentuk jalan yang memotong dan bercabang dengan sumbu pada pusat kawasan (sekitar masjid) yaitu mekke keke yang dianalogikan sebagai miniatur Masjidil Haram. Secara topografi area mekka keke memiliki ketinggian berbeda dengan area permukiman. Sirkulasi utama yang bercabang mengarah pada mekka keke dengan sebaran bangunan berfungsi sosial seperti masjid, lapangan terbuka, possi tanah, pakkojokang dan pemakaman. Sedangkan area perkebunan umumnya berada diluar kegiatan permukiman. Pola tata ruang model linear seperti ini juga ditemukan pada desa tradisional di beberapa daerah. Permukiman tradisional suku Sasak di Lombok Timur berkembang dengan pola linear mengikuti jalan ke arah timur dengan area bale adat (Sabrina, Anatriksa dan Prayitno, 2010). Pola permukiman Dusun Ngibikan Yogyakarta juga memiliki orientasi jalan, sungai, gunung, atau arah suci (Wiraprama, Zakaria dan Purwaningtiasning, 2014).

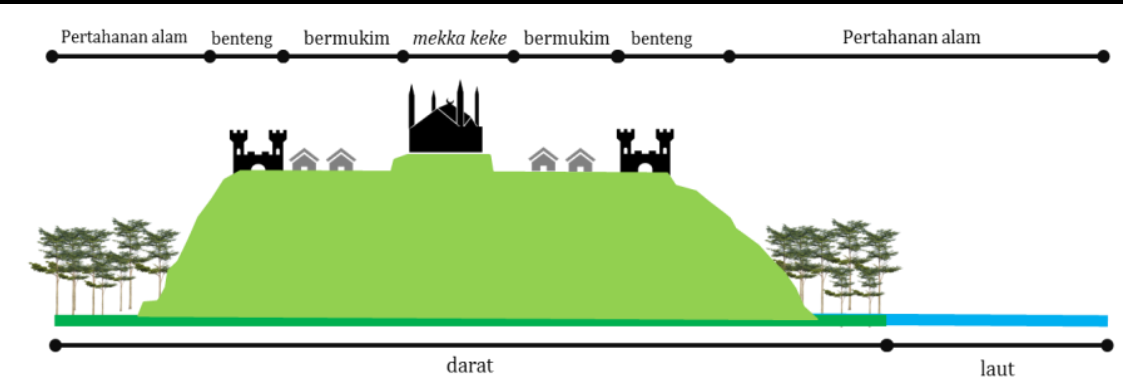

Sumber : Hasil Analisis, 2017

Gambar 3. Pemanfaatan Karaktersitik Topografi 
Batas kampung ditandai dengan benteng yang mengelilingi kawasan. Struktur material benteng menggunakan bahan alami yang terdiri dari 4 pintu yang dihubungkan dengan bentangan susunan batu yaitu :

- Pintu barat (babaang lembang-lembang), yang berbatasan dengan jalan utama berukuran tinggi $200 \mathrm{~cm}$ dan lebar $60 \mathrm{~cm}$, masyarakat setempat menyakini bahwa pintu ini dijaga oleh seekor kerbau

- Pintu timur (babaang turungang), yang berbatasan dengan Teluk Turungan dengan tinggi $135 \mathrm{~cm}$ dan lebar $60 \mathrm{~cm}$ dan dijaga oleh seekor kuda.

- Pintu selatan (babaang sele), yang berbatasan dengan Teluk Babaere dengan tinggi 100 $\mathrm{cm}$ dan lebar $60 \mathrm{~cm}$ yang djaga oleh seekor kerbau.

- Pintu rahasia (babaang manrusu) yang berbatasan dengan gua yang selanjutnya menuju Teluk Turungang tinggi $160 \mathrm{~cm}$ dan lebar $60 \mathrm{~cm}$.

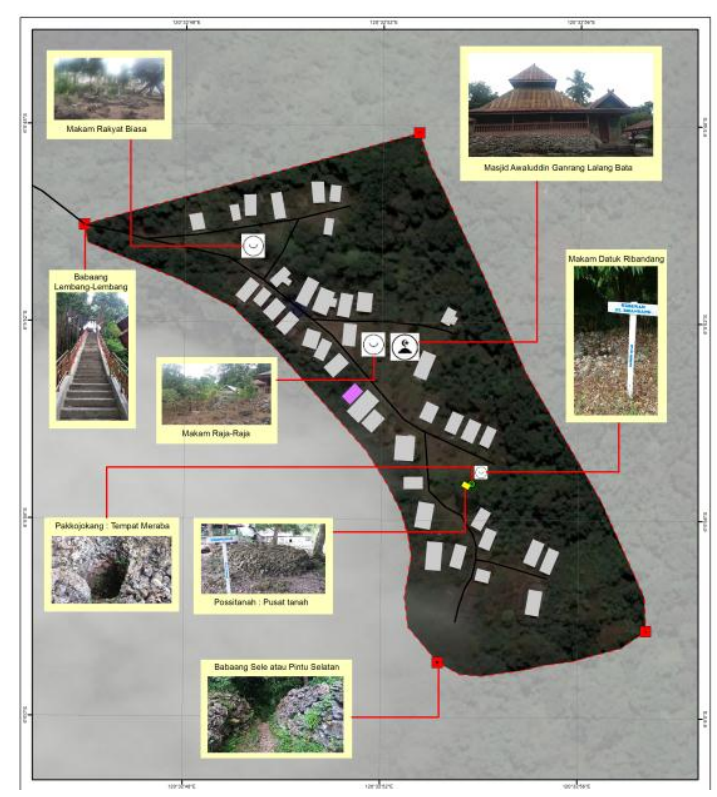

Sumber : hasil analisis, 2017

\section{Gambar 4. Pola Tata Ruang Permukiman}

\section{DISKUSI}

Dalam perkembangannya kampung tua Gantarang Lalang Bata dipengaruhi oleh berbagai budaya yaitu Hindu, Jawa, Belanda dan Arab yang menciptakan bentuk akulturasi budaya seperti kampung tradisional lainnya. Akulturasi adalah proses penggabungan antara dua kebudayaan atau lebih untuk mencari jalan tengah di mana pada kebudayaan baru yang terbentuk tersebut masih dapat ditemukan karakter asli dari unsur-unsur kebudayaan penyusunnya (Jamalie, 2014). Budaya memiliki sifat kolektif karena pada batasan tertentu selalu bersosialisasi dengan orang-orang yang hidup di lingkungan sosial dimana mereka akan saling mengadopsi (Hofestede, 2007 dalam Cenek dan Hrabalaek, 2016).

Unsur budaya Hindu yang bercirikan kegiatan ritual dengan menggunakan kemenyan dan menyiapkan sesajen (Ahmadin, 2006). Hal ini juga mempengaruhi pola kebiasaan 
masyarakat setempat, dimana secara realitas masih menyiapkan sesajen berupa songkolo dengan 3 warna pada upacara adat maupun hari keagamaan yang kemudian didoakan dan dimakan bersama. Pada sisi yang berbeda juga tampak pada pakkammikyaitu kepercayaan terhadap penghuni atau penjaga kampung, gunung atau benda-benda lainnya yang biasanya diasosiasikan dengan bentuk hewan ataupun sesuatu yang keramat. Kepercayaan tersebut juga merujuk pada kepercayaan masyarakat terhadap penjaga 3 pintu yang dijaga oleh kuda dan kerbau. Masyarakat asing yang memasuki kawasan tersebut, diharuskan untuk menempelkan dahi pada sebidang batu yang ada pada baabang lembang-lembang sebagai bentuk penghargaan terhadap penjaga pintu tersebut (Gambar 5.a). Model kepercayaan tersebut memiliki kesamaan dengaan tradisi kelompok masyarakat di Sulawesi Selatan seperti kepercayaan masyarakat terhadap penjaga Gunung Bawakaraeng di Gowa atau bulu' lowa di Amparita (Pabbajah, 2012). Masyarakat adat kalampang di Wajo mempercayai adanya penguasa Danau Tempe pada area tertentu, sehingga masyarakat harus menjaga sikap dan perilaku (Surur, 2015).

Identitas budaya Jawa dalam kampung teridentifikasi pada bentuk bangunan Masjid Awaluddin sangat kental dengan arsitektur langgam Jawa. Atap bersusun tumpang dimana semakin ke atas semakin mengecil dan tingkatan paling atas berbentuk limas (Gambar 5.b). Pada Masjid Agung Demak memiliki model yang sama berupa atap tajug bertumpang, didukung oleh sokoguru dan sebuah mustaka di puncaknya (Ashadi, 2002). Hal yang sama juga dapat diamati pada Masjid Al Hilal Katangka Gowa, dimana juga menggunakan protipe khas Mataram Islam dengan ciri khas atap tumpang (Idham, 2009). Atap tumpang merupakan bentuk perkembangan dari dua unsur berlainan yaitu atap candi denahnya bujur sangkar, selalu berundak dan puncak stupa yang adakalanya berbentuk payung terbuka (Soekamono, 1973).

Pola tata ruang juga dipengaruhi oleh unsur budaya Eropa, namun tidak menonjol dibanding elemen lainnya. Pengaruh Eropa hanya tampak pada keberadaan latto atau meriam berukuran 2 meter (Gambar 5.c). Keberadaan meriam di sekitar masjid menandakan bahwa masyarakat setempat pada masanya telah melakukan kontak dengan orang-orang Eropa. Meriam sebagai atribut permukiman juga dapat ditemukan pada kampung Mekian Maluku, dimana terdapat meriam di sekitar Keraton Sultan Bacan (Salhateru, 2007). Ciri kolonial juga tampak pada kota tua di Surabaya, bastion lengkap dengan persenjataan meriam-meriam sebagai struktur kota bawah (Aini, 2013)
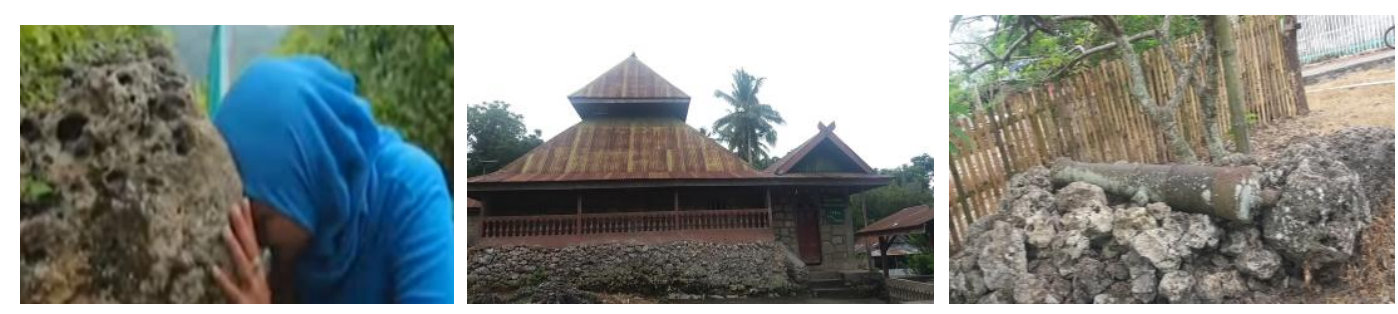

Sumber : hasil analisis, 2017

\section{Gambar 5. (a) Unsur Hindu, (b) Unsur Jawa, (c) Unsur Eropa}

Secara umum pengaruh Islam sangat dominan pada bentuk pola tata ruang kampung tua Gantarang Lalang Bata. Hal ini diwujudkan dalam area mekka keke yang terdiri possi tanah, pakkojokang, Masjid Awaluddin dan tapak kaki sebagai bentuk simbolisasi dari bentuk tata ruang Masjidil Haram di Mekkah. Pengaruh Islam tidak hanya berasosiasi dengan elemen tangible tetapi juga pada elemen intangible. Kegiatan ibadah Jumat, Idul Adha dan Idul Fitri masih menggunakan naskah khutbah yang dibacakan oleh khatib 
dengan menggunakan bahasa Arab, selain itu tata cara ibadah menunjukkan kesamaan dengan pelaksanaan ibadah di Mekkah. Dato Ri Bandang secara penuh mengadopsi tradisi muslim dalam proses penyebaran agama Islam di kampung tersebut. Masyarakat setempat menggunakan ruang mekka keke sebagai media dalam ritual ibadah manasik haji. Awalnya mekka keke hanya berfungsi sebagai sarana dalam manasik haji akan tetapi karena akulturasi budaya Hindu maka masyarakat setempat mensakralkan area ini sebagai area keramat.
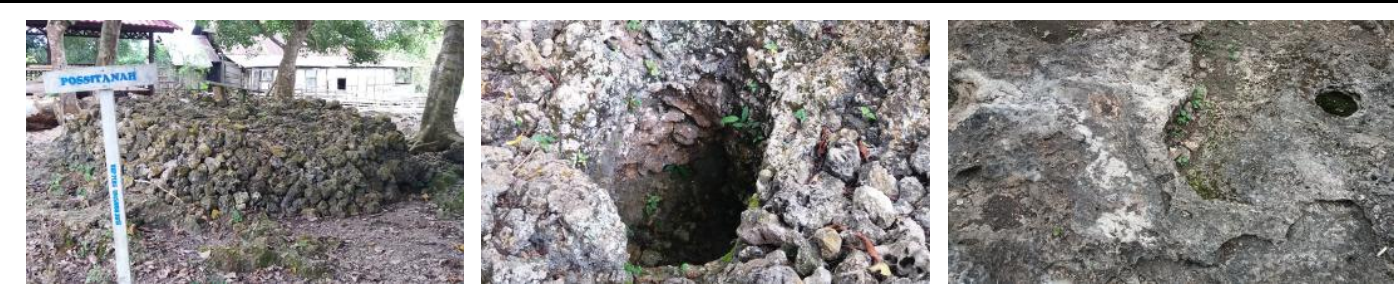

Sumber : hasil analisis, 2017

\section{Gambar 6. (a) possi tanah, (b) pakkojokang, (c) tapak kaki}

Konsep arsitektur Islam mengacu pada karakteristik bangunan yang digunakan oleh umat Islam dan berfungsi sebagai identitas mereka (Bouayad, 2007). Kota Basra, Kufah, Mosul dan kota-kota lainnya di Irak memiliki karakteristik pola kota Islam dengan menempatkan masjid di tengah kota dan kemudian didukung dengan keberadaan sebaran permukiman yang sejajar (Ali dan Nangkula, 2012). Perkembangan kota-kota tradisional di Indonesia umumnya masih dipengaruhi oleh budaya Islam-Jawa. Salah satu kota dengan corak tersebut yaitu Kota Surakarta dengan struktur berupa keraton, alun-alun dan masjid. Struktur semacam ini merupakan prototipe kota kerajaan Mataram Islam (Junianto, 2012). Hal yang sama juga ditemukan pada pola tata ruang Kota Palopo dengan atribut utama berupa Masjid Jami, lapangan dan Istana Luwu yang saling berintegrasi (Surur, 2013). Mekka keke membetuk ciri kota yang dipengaruhi oleh model kota Mataram Islam yaitu adanya masjid, alun-alun atau lapangan terbuka dan makam yang saling terhubung. Namun model representasi tata ruang Masjidil Haram tersebut mengindikasikan hal yang berbeda dimana tidak ditemukan pada kota-kota yang mendapatkan pengaruh Mataram Islam.

Mekka keke sebagai pusat perkembangan kegiatan sosial dan keagamaan dapat dinilai sebagai inti atau sense of place dalam sistem kampung tua Gantarang Lalang Bata. Lynch (1972) dalam Purwanto (2011) mengungkapkan bahwa identitas diperlukan bagi seseorang untuk membentuk kepekaannya terhadap suatu tempat, dan bentuk paling sederhana dari kepekaan ruang (sense of place) adalah identitas. Sebuah kesadaran dari seseorang untuk merasakan sebuah tempat berbeda dari yang lain, yaitu sebuah tempat memiliki keunikan, kejelasan, dan karakteristik sendiri. Kepekaan ini tidak hanya tergantung kepada bentukbentuk spasial dan kualitasnya, tetapi juga pada budaya, temperamen, status, pengalaman, dan peranan pengamat, sedangkan inamika kota terbentuk lewat interaksi antara orang dan ruang (Purwanto, 2001).

Sistem pembentuk citra kampung tua Gantarang Lalang Bata menunjukkan bahwa elemen - elemen tersebut semakin kuat membentuk karakter berasosiasi dengan bentuk permukiman Muslim. Semua kota yang dihuni oleh masyarakat Muslim memiliki berbagi identitas Islam yang secara langsung sebagai bentuk penerapan nilai-nilai syariat dalam kehidupan sehari-hari (Correia \& Taher, 2015). Keberadaan Masjid Awaluddin merupakan simbol Islamisasi yang kuat. Pada dasarnya area mekka keke tidak hanya berfungsi sebagai pusat keagamaan tetapi juga memiliki fungsi sosial, pendidikan dan sebagai pusat 
administrasi kerajaan. Penerapan syariat Islam dapat merujuk pada pembentukan aktivitas masyarakat setempat. Kegiatan shalat Jumat, Idul Fitri dan Idul Adha sangat identik dengan pelaksanaan ibadah di Mekkah yaitu dengan menggunakan naskah khutbah dalam bentuk bahasa Arab.

Perkembangan tata ruang Gantarang Lalang Bata tidak terlepas dari pengaruh berbagai unsur budaya dengan catatan sejarah yang berbeda kemudian menyatu dengan satu sistem tata ruang yang khas. Akulturasi budaya menguatkan citra kawasan dengan unsur budaya masing-masing walaupun pada akhirnya budaya Islam sangat berpengaruh kuat dibanding dengan unsur budaya lainnya. Unsur budaya yang berbeda saling menyesuaikan diri dengan kondisi dan suasana kebudayaan yang ada sehingga menciptakan suatu keharmonisan dengan lingkungannya. Sistem tata ruang juga membentuk kesatuan antara unsur manusia berserta budayanya dengan unsur karakteristik alamnya.

\section{KESIMPULAN}

Elemen tata ruang kampung tua Gantarang Lalang Bata berupa elemen tangible dan intangible yang berasosiasi dengan unsur manusia dan unsur alam. Karakteristik alam yang berbukit mempengaruhi pola tata ruang kawasan yang dimanfaatkan sebagai bentuk pertahanan dan keamanan. Beberapa unsur budaya yang saling berharmonisasi dalam sistem permukiman. Budaya corak Hindu yang mengarah pada tradisi pakammik, unsur Jawa merujuk pada bangunan masjid, keberadaan meriam sebagai atribut unsur Eropa dan tradisi serta tata ruang berasosiasi dengan pengaruh Arab. Pengaruh budaya Jawa - Islam menjadi sisi yang paling dominan mempengaruhi sistem permukiman baik secara fisik dan non fisik. Bentuk akulturasi budaya tersebut juga menciptakan sense of place yang merujuk pada area mekka keke sebagai inti dari kawasan tersebut. Secara umum kampung tua Gantarang Lalang Bata menunjukkan bentuk permukiman dengan perpaduan tradisi yang khas, dengan memanfaatkan unsur alam di wilayah tersebut.

\section{DAFTAR PUSTAKA}

Ahmadin, A. (2006). Warisan Budaya Orang Selayar (Menggugat Eksistensi Atas Nama Identitas.. Jurnal Jaffray, 4(1).

Aini, M. K. (2013). Masyarakat Arab Islam di Ampel Surabaya dalam Struktur Kota Bawah (Kota Belanda) 1816 1918 (Dosertasi S3, UIN Sunan Ampel Surabaya).

Arikunto, Suharsini. (2002). Prosedur Penelitian. Yogyakarta : Rineka Cipta.

Aryanto, A., Wahid, J., Aulia, D. A., \& Suriadi. A. (2005). Kajian Pembentuk Citra Kawasan Perumahan Studi Kasus: Perumahan Taman Setiabudi Indah Medan. Jurnal Arsitektur ATRIUM. 2(2).

Asba, A.R (2005). Merajut Simpul Budaya Selayar Pulau Niaga Nusantara. Disampaikan Dalam Seminar Sehari Lawatan Sejarah Tingkat Nasional pada Tanggal 16-21 Agustus 2005. Depdiknas.

Ashadi. (2002). Masjid Agung Demak sebagai proptipe Masjid Nusantara: Filosofi Aristketur. NALARs, 1(1), 110.

Bouayad. A, H. (2007). The Reference Architecture We Have a Reference Text. Aharrov Magazine. Rabat

Cenek, J., \& Hrabalaek, M. (2016). Cultural Adaptation of Czech Citizen in The Republic Of Turkey. Jurnal of education cultue and society, 2, 111-127.

Fowler, P. (2003). World Heritage Cultural Landscapes 1992-2002, World Heritage Papers. UNESCO World Heritage Centre, Paris.

Idham. (2009). Akulturasi Budaya pada Arsitektur Masjid Tua Katangka, Gowa Sulawesi Selatan. Jurnal Lektur Keagamaan. 7 (2), 253-274.

Ilyas, H. F. (2014) Islamisasi Selayar Abad XV; Kajian Naskah. Jurnal Lektur Keagamaan, 12(1), 105 - 126.

Jamalie, Z. (2014). Akulturasi dan Kearifan Lokal dalam Tradisi Baayun Maulid Pada Masyarakat Banjar. el Harakah, 16(2), 234-254.

Junianto. (2002). Pola Struktur Kota Surakarta dalam lingkup Pengaruh Pembangunan Masjid Agung pada masa kerjaan Mataram Islam, Seminar Nasional Arsitektur Islam 2 tahun 2012.

Koentjaraningrat. (1990). Pengantar Ilmu Antropologi. Jakarta: Universitas Indonesia Press. 
Lowenthal, D. (2006). Natural and cultural heritage. In The Nature of Cultural Heritage and the Culture of Natural Heritage: Northern Perspectives on a Contested Patrimony; Olwig, K.R., Lowenthal, D., Eds.; Routledge: New York, NY, USA.

Nurisjah S, Pramukanto Q. (2001). Perencanaan Kawasan untuk Pelestarian Lanskap dan Taman Sejarah. (Skripsi S1, Institut Pertanian Bogor, 2001. Tidak untuk dipublikasikan).

Pabbajah, M. (2012). Religiusitas dan Kepercayaan Masyarakat Bugis-Makassar. Jurnal Al- Ulum, 12(2), 397418.

Pemerintah Kabupaten Kepulauan Selayar. (2012). Peraturan Daerah Nomor 5 Tahun 2012 tentang Rencana Tata Ruang Wilayah Kabupaten Kepulauan Selayar 2012-2032. Benteng: Kabupaten Kepulauan Selayar.

Plachter, H. \& Rossler, M. (1995). Cultural Landscape: Reconnecting Culture and Nature. In: van Droste, B., Placher, H., Rossler, M. (eds.) Cultural Landscape of Universal Value. Jena : Gustav Fischer.

Purwanto, E. (2004). Pendekatan Pemahaman Citra Lingkungan Perkotaan (melalui kemampuan peta mental pengamat). DIMENSI (Journal of Architecture and Built Environment), 29(1).

Sabrina R, Antariksa \& Prayitno G. Pelestarian Pola Permukiman Tradisional Suku Sasak Dusun Limbungan Kabupaten Lombok Timur. Jurnal Tata Kota dan Daerah, 1(2), 87-180.

Said, A. M., Ramli, M., \& Sumantri, I. (2007). Direktori Potensi Wisata Budaya di Kawasan Karst MarosPangkep Sulawesi Selatan Indonesia. Makassar : Direktorat Jenderal Kebudayaan.

Salhuteru, M. (2007). Peninggalan Kolonial di Kampung Makian. Kapata Arkeologi, 3(5), 107-115.

Soekamono, R. (1973). Pengantar Sejarah Kebudayaan Indonesia I - III. Yogyakarta: Kanisius.

Somantri, G.R. (2005). Memahami Metode Kualitatif. Makara, 9 (2), 57-65.

Surur, F. (2013). Penataan dan Pelestarian Kawasan Bersejarah Kota Palopo sebagai Kota Pusaka Indonesia. Seminar Ikatan Peneliti Lingkungan Binaan ke II. Universitas Hasanuddin.

Surur, F. (2015). Strategi Adaptasi Nelayan terhadap Perubahan Ekologis Danau Tempe di Desa Pallimae Kecamatan Sabbangparu Kabupaten Wajo. Plano Madani, 4(1).

Tubbs, L. S., \& Sylvia, M. (2001). Human Comunication (konteks konteks komunikasi). Bandung: PT. Remaja Rosdakarya.

Vos, W., \& Meekes, H. (1999). Trends in European cultural landscape development: perspectives for a sustainable future. Landscape and Urban Planning, 46(1). 3-14.

Wang, C.H. (2015) Using remote sensing technology on the delimitation of the Conservation area for the jianan irrigation system cultural Landscape. The International Archives of the Photogrammetry, Remote Sensing and Spatial Information Sciences, Volume XL-5/W7, 2015 25th International CIPA Symposium 2015, 31 August - 04 September 2015, Taipei, Taiwan.

Wiraprama, A.R., Zakaria., \& Purwantiasning, A.R. (2014) Kajian Pola Permukiman Dusun Ngibikan Yogyakarta Dikaitkan dengan Perilaku Masyarakatnya. Jurnal Arsitektur NALARs, 13(1), 31-36.

Yassin, A. A \& Nangkula, U. Architecture in The Islamic Civilization: Muslim Building or Islamic Architecture. Journal of Islamic Architecture, 2(2),52-60.

Yunus, A.R. (2014). Sejarah Awal Masuknya Islam di Selayar. Jurnal Rihlah, 1(2).

Zonneveld, I. S. (1981): Land(scape) ecology, a science or a state of mind. - In: Tjallingii, S. P. \& de Veer, A. A. (Eds.): Perspectives in Landscape Ecology. - Proceedings of the International Congress organized by the Netherlands Society for Landscape Ecology, Veldhoven 1981, 9 - 15; Wageningen. 